\title{
Tobacco consumption and positive mental health: an epidemiological study from a positive psychology perspective
}

Juan Carlos Bazo-Alvarez ${ }^{1,2^{*}}$, Frank Peralta-Alvarez ${ }^{1}$, Antonio Bernabé-Ortiz', Germán F. Alvarado² and J. Jaime Miranda ${ }^{1,3}$

\begin{abstract}
Background: Positive mental health (PMH) is much more than the absence of mental illnesses. For example, PMH explains that to be happy or resilient can drive us to live a full life, giving us a perception of well-being and robustness against everyday problems. Moreover, $\mathrm{PMH}$ can help people to avoid risky behaviours like tobacco consumption (TC). Our hypothesis was that PMH is negatively associated with TC, and this association differs across rural, urban and migrant populations.

Methods: A cross-sectional study was conducted using the PERU MIGRANT Study's dataset, including rural population from the Peruvian highlands $(n=201)$, urban population from the capital city Lima $(n=199)$ and migrants who were born in highlands but had to migrated because of terrorism ( $n=589$ ). We used an adapted version of the 12-item Global Health Questionnaire to measure PMH. The outcome was TC, measured as lifetime and recent TC. Log-Poisson robust regression, performed with a Maximum Likelihood method, was used to estimate crude prevalence ratios (PR) and $95 \%$ confidence intervals $(95 \% \mathrm{Cl})$, adjusted by sex, age, family income and education which were the confounders. The modelling procedure included the use of LR Test, Akaike information criteria (AIC) and Bayesian information criteria (BIC).

Results: Cumulative occurrence of tobacco use (lifetime TC) was $61.7 \%$ in the rural group, $78 \%$ in the urban group and $76.2 \%$ in rural-to-urban migrants. Recent TC was $35.3 \%$ in the rural group, $30.7 \%$ in the urban group and $20.5 \%$ in rural-to-urban migrants. After adjusting for confounders, there was evidence of a negative association between $\mathrm{PMH}$ and lifetime TC in the rural group ( $\mathrm{PR}=0.93 ; 95 \% \mathrm{Cl}: 0.87-0.99)$, and a positive association between PMH and recent TC in migrants ( $P R=1.1 ; 95 \% \mathrm{Cl}: 1.0-1.3)$.

Conclusions: PMH was negatively associated with TC in rural participants only. Urbans exhibited just a similar trend, while migrants exhibited the opposite one. This evidence represents the first step in the route of knowing the potential of PMH for fighting against TC. For rural populations, this study supplies new information that could support decisions about prevention programmes and psychotherapy for smoking cessation. However, more research in the topic is needed.
\end{abstract}

Keywords: Tobacco Consumption, Positive Mental Health, Positive Psychology, GHQ-12, Rural Population, Rural-to-Urban Migrant

\footnotetext{
* Correspondence: juan.bazo.a@upch.pe

${ }^{1}$ CRONICAS Center of Excellence in Chronic Diseases, Universidad Peruana Cayetano Heredia, Av. Armendáriz 497Miraflores, Lima, Peru

${ }^{2}$ School of Public Health and Administration, Universidad Peruana Cayetano Heredia, Lima, Peru

Full list of author information is available at the end of the article
}

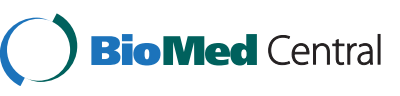

(C) 2016 Bazo-Alvarez et al. Open Access This article is distributed under the terms of the Creative Commons Attribution 4.0 International License (http://creativecommons.org/licenses/by/4.0/), which permits unrestricted use, distribution, and reproduction in any medium, provided you give appropriate credit to the original author(s) and the source, provide a link to the Creative Commons license, and indicate if changes were made. The Creative Commons Public Domain Dedication waiver (http://creativecommons.org/publicdomain/zero/1.0/) applies to the data made available in this article, unless otherwise stated. 


\section{Background}

'It is much better to be wealthy and happy than poor and sick', a famous quote attributed to Johann Nestroy [24], implicitly suggests the widely held idea that health is merely the opposite of sickness. Although this may be acceptable enough in general medicine, it is certainly not in mental health. Today, we are still trying to expand our understanding of mental health beyond a no-sickness status $[24,45]$. Currently, positive mental health $(\mathrm{PMH})$ emerges as an expression of a healthy mind, a balanced emotional life and a strong personality. Happiness, resilience, well-being and optimism - features that are trainable [46] - are some of the features that define $\mathrm{PMH}$ in every person. By improving these positive attributes in clients/patients, clinical psychologists and psychiatrists could help to ameliorate some signs and symptoms of common 'mental disorders' [30,46], including tobacco addiction. In other words, clinicians can reinforce their traditional treatment strategies with those from applied positive psychology (the present school of $\mathrm{PMH}$ ). Moreover, $\mathrm{PMH}$ is potentially useful for prevention in healthy people (avoiding relapses). In this study we present preliminary evidence for the potential utility of $\mathrm{PMH}$ in preventive clinical practice and epidemiology, by exploring its relationship with tobacco consumption (TC) in naturalistic, non-experimental contexts.

$\mathrm{TC}$ is a risky behaviour that represents a concern for public health in low and middle income countries (LMIC), where prevalence of smokers ranks from $16.0 \%$ to $43.3 \%$ [40]. In Peru, reported tobacco users were more severe among rurals (median of 10 cigarettes per month) than among urbans (median of 5.5 per month) or migrants (median of 5 cigarettes per month) [35]. A higher prevalence of tobacco use in rurals has been confirmed in other countries such as India [13] and Mozambique [38]. Furthermore, recent evidence shows how a telephone-based tobacco cessation programme was less effective for rurals than urbans [18]. In sum, TC is a LMIC problem that remarks the inequality between rural and urban populations, claiming mental health studies that can explore alternatives of solutions for both populations.

For positive psychology, the study of the relationship between (positive) mental health and tobacco consumption is an emerging activity, still lacking definitive conclusions. Early evidence showed how cigarette smoking is negatively related to well-being (defined as general satisfaction with own life, including relationships, financial situation, physical and psychological health) [39], and how women who have never smoked had higher levels of well-being than similar ex-smokers and current smokers [15]. Self-efficacy (defined as an individual's self-perceived ability to cope with stressful or challenging demands, including tobacco or alcohol abstinence) seems to be a strong factor for smoking control in clinical intervention contexts [47]. An increase in resilience (defined as the ability to adapt properly to stressful or extreme situations in life) was accompanied by a reduction in tobacco consumption in high-school students [22]. Optimism (defined as positive perceptions of own life and future) and its relationship with unhealthy habits was studied in 31-year-old men and women, with the results indicating that the proportion of current smokers was higher among pessimists than among optimists [29]. Autonomy (defined as autonomous motivation for initiating and sustaining cessation from smoking, and taking cessation medication) has also been studied as a predictor of smoking cessation while interventions based on self-determination theory have shown their positive effectiveness [49, 50]. In sum, all these studies show evidence of strong and inverse associations between positive mental health indicators and tobacco use.

The mechanisms that explain how people with $\mathrm{PMH}$ may be protected against TC can be described as follows. Happiness in these people could be a reflection of their strong personal resources for coping with life; for example, being optimistic about the future or knowing how to face daily difficulties. These people are more protected against depressive episodes and recurrent anxiety [3], both known predictive factors of TC [9]. Resilience is a positive attribute, especially important in critical life situations $[25,42]$; it makes a person less likely to relapse into TC. Self-acceptance and self-efficacy are feelings associated with strength of character, independence and a self-supporting personality, which protects against tobacco consumption associated with peer pressure. These attributes are especially important in adolescence, when consumption behaviour has a better prognosis of sustainability [10]. In this situation, $\mathrm{PMH}$ can operate as a protective factor against TC, especially for consumers who do not have mental disorders as comorbidity. Indeed, the first hypothesis that we assessed in our study is "there is an inverse association between PMH and TC".

In reviewing the literature it is apparent that there is a need for a more integrative measurement of $\mathrm{PMH}$ when its relationship with $\mathrm{TC}$ is studied. As we have seen above, most researchers have studied different aspects of PMH and its relationship with TC separately. However, people typically have more than one positive attribute behind a unique functioning of $\mathrm{PMH}$, so while one operates the others can have a more discrete action. This circumstance is relevant when the association between PMH and TC is studied: to measure PMH indicators separately can give an incomplete or biased picture of the relationship. It is opportune to remark that $\mathrm{PMH}$ has been previously measured [16, 33, 42] and handled [37] like a unique construct, and this is an 
important aspect to be tapped into by researchers and promoters.

From an epidemiological perspective, it is relevant to know if an association between $\mathrm{PMH}$ and $\mathrm{TC}$ is generalizable across diverse populations. Psychologists usually affirm that psychological features are culturally bound, as people from different cultures can have different cognitive and behavioural responses to the same stimulus [7]. Since we are interested in obtaining conclusions that are valid inter-culturally, our intention of exploring the relationship between PMH and TC across three important groups in LMIC (rurals, urbans and migrants) is justified. Especially for rurals and migrants there is a lack of information about positive mental health topics. As far as we know, these three populations have shown important differences in terms of traditions, risk behaviours, acculturation, social capital and mental health $[31,51]$. Other previous studies have showed that associations between cigarette smoking and some of its known related factors (education and income) differ between non-migrants and rural-tourban migrants [11], as well as income has a moderation effect on depression that affect cigarette smoking in migrants [12]. Moreover, some positive features such as well-being and self-determination are influenced by the acculturation process of migrants [17]. When this process is not completed, migrants retain particular characteristics that make them different from non-migrants, at least in one of three levels: intrapersonal, interpersonal and citizenship [17]. Considering these evidences, we conclude that an exploration of the association between $\mathrm{PMH}$ and TC across these three populations is needed, and differences between them are anticipatable. Indeed, the second hypothesis that we assessed is "the association between PMH and TC differs across rural, urban and migrant populations (the potential effect modifier) because of their psychological and socioeconomic differences".

To address the gaps identified above, we applied an alternative $\mathrm{PMH}$ instrument and compared rural, urban and migrant populations. We have used a general PMH instrument that includes items about happiness, resilience, self-efficacy and self-acceptance to provide a more global perspective of PMH. In addition, we have explored this relationship with regard to three Peruvian populations with known socio-cultural differences: rural non-migrants, urban non-migrants and rural-to-urban migrants [31]. Urban populations are from the coastal areas of Peru and tend to have better economic conditions and access to educational and health services because they live in or near to metropolitan areas. Rural populations include people from the highlands, residing in rural places where poverty and a low quality of educational and health services are common. Migrants are persons who had to migrate from rural settings to the metropolis because of terrorist violence in Peru during the 1980s and 1990s.

In sum, the aim of this investigation is to evaluate the evidence of an association between PMH and tobacco consumption (first hypothesis) and how this association differs across rural, urban and migrant populations (second hypothesis).

\section{Methods \\ Study design}

This study is a secondary data analysis using crosssectional information from the PERU MIGRANT Study. This study was focused on the exploration of differences in cardiovascular risk factors in rural, urban and rural-tourban migrants in Peru. However, other relevant information was collected, included socio-demographic and mental health outcomes. The questionnaire was administered by trained pollsters, during interviews of $30-40 \mathrm{~min}$. All the questions were done in Spanish, but for non-Spanish speakers a translation was done by pollsters. The aims and methods of this study have already been published and explained in detail $[31,34,51]$.

\section{Participants}

Participants were from three populations: non-migrants and residents in the rural zone $(n=201)$, non-migrants and residents in the urban zone $(n=199)$ and rural-tourban migrants and residents in the urban zone $(n=589)$. The sampling design included stratification by age and sex, where a random selection was applied to every stratum in order to obtain proportional sizes of participants (see Table 1). The inclusion criteria were to be at least 30 years old and the exclusion criteria was not to agree to participate in the study. Each participant in the sample list was visited at home by pollsters. The urban zone was located in Lima, Peru's capital city. The rural zone was in Ayacucho, a region located in the Peruvian Andes. Migrants were defined as those who moved from Ayacucho to Lima and currently live in Lima. Inclusion and exclusion criteria for this study did not differ from the original study [34].

\section{Variables and conceptual model}

In our conceptual model, the primary outcome was tobacco consumption and the main exposure was PMH. We considered sex, age, education and family income as potential confounders. We also considered that being part of a specific population (rural, urban or migrant) may interact with $\mathrm{PMH}$, thereby affecting tobacco consumption as a potential effect modifier.

\section{Instruments}

To assess tobacco consumption (TC), we used two different measures: lifetime TC and recent TC. The question 
Table 1 Distribution of sex, age, education, income, Positive Mental Health and tobacco consumption by rural, migrant and urban groups in Peru. The PERU MIGRANT study, 2009

\begin{tabular}{|c|c|c|c|c|c|c|c|}
\hline & \multirow{2}{*}{\multicolumn{2}{|c|}{$\begin{array}{l}\text { Rural } \\
(N=201)\end{array}$}} & \multirow{2}{*}{\multicolumn{2}{|c|}{$\begin{array}{l}\text { Migrant } \\
(N=589)\end{array}$}} & \multirow{2}{*}{\multicolumn{2}{|c|}{$\begin{array}{l}\text { Urban } \\
(N=199)\end{array}$}} & \multirow{3}{*}{$p^{*}$} \\
\hline & & & & & & & \\
\hline & $n$ & $(\%)$ & $n$ & (\%) & $n$ & (\%) & \\
\hline \multicolumn{8}{|l|}{ Sex } \\
\hline Male & 95 & 47.3 & 280 & 47.5 & 92 & 46.2 & \multirow[t]{2}{*}{0.95} \\
\hline Female & 106 & 52.7 & 309 & 52.5 & 107 & 53.8 & \\
\hline \multicolumn{8}{|l|}{ Age (years) } \\
\hline $30-39$ & 61 & 30.4 & 154 & 26.2 & 54 & 27.1 & \multirow[t]{4}{*}{0.38} \\
\hline $40-49$ & 55 & 27.4 & 178 & 30.3 & 51 & 25.6 & \\
\hline $50-59$ & 48 & 23.9 & 173 & 29.5 & 61 & 30.7 & \\
\hline $60-99$ & 37 & 18.4 & 82 & 14.0 & 33 & 16.6 & \\
\hline \multicolumn{8}{|l|}{ Education } \\
\hline without studies & 68 & 33.8 & 59 & 10.0 & 2 & 1.0 & \multirow[t]{4}{*}{$<0.001$} \\
\hline primary & 94 & 46.8 & 223 & 37.9 & 34 & 17.2 & \\
\hline secondary & 33 & 16.4 & 242 & 41.2 & 107 & 54.0 & \\
\hline superior & 6 & 3.0 & 64 & 10.9 & 55 & 27.8 & \\
\hline \multicolumn{8}{|l|}{ Income } \\
\hline$<=160$ soles (US\$ 50$)$ & 109 & 69.0 & 8 & 1.4 & 2 & 1.0 & \multirow[t]{4}{*}{$<0.001$} \\
\hline between 161-480 soles (US\$ 51-150) & 32 & 20.3 & 143 & 25.8 & 36 & 18.7 & \\
\hline between 481-800 soles (US\$151-250) & 10 & 6.3 & 292 & 52.6 & 104 & 53.9 & \\
\hline$>=801$ soles $(>=$ US\$251) & 7 & 4.4 & 112 & 20.2 & 51 & 26.4 & \\
\hline \multicolumn{8}{|l|}{ Positive Mental Health } \\
\hline (mean(standard deviation)) & 198 & $(5.9(1.9))$ & 483 & $(6.5(1.8))$ & 163 & $(6.8(1.8))$ & $<0.001$ \\
\hline \multicolumn{8}{|l|}{ Tobacco Consumption (TC) } \\
\hline Lifetime TC & 124 & 61.7 & 441 & 76.2 & 154 & 78.2 & $<0.001$ \\
\hline Recent TC & 71 & 35.3 & 121 & 20.5 & 61 & 30.7 & $<0.001$ \\
\hline$N^{\circ}$ cigarettes in the last 30 days (median(iqr range)) & 6 & $(10(1-20))$ & 37 & $(5(3-20))$ & 32 & $(5.5(1-26.5))$ & 0.95 \\
\hline
\end{tabular}

${ }^{*}$ Chi-square test for categorical variables, ANOVA oneway for positive mental health and Kruskal-Wallis for $\mathrm{N}^{\circ}$ cigarettes in the last 30 days Lifetime TC: Have you ever smoked a cigarette? Current TC: Are you currently smoker? or Have you smoked in the last six months? Source: PERU MIGRANT Study dataset

'Have you ever smoked a cigarette?', the lifetime prevalence (cumulative occurrence) question, served to evaluate lifetime TC. This question had three answer choices: 1) yes, 2) yes, but just once to try, and 3) no. The first and second responses were collapsed as one category (yes) of consumption (dichotomic outcome). To assess recent TC, we used cross-referenced information from two questions: 1) When was the last time you smoked? and 2) How many cigarettes have you smoked in the last month? A participant is considered a recent smoker if 1 ) he/she declared that they smoked in the last six months, or 2) he/she declared that they smoked at least one cigarette in the last month.

PMH was measured by an adaptation of the General Health Questionnaire (GHQ-12), designed and validated previously in two steps (see Additional file 1).
The first step included content validation, where items from GHQ-12 were contrasted with items from other tests especially designed for measuring $\mathrm{PMH}$ or its more important indicators, such as happiness [2], resilience [41], self-efficacy [43] and self-acceptance [14]. This procedure is supported by the proposal of Joseph and Wood [27], who maintain that positive constructs can be measured by tests originally designed for clinical and psychopathological purposes. A second step consisted of a psychometric revision of reliability and validity using quantitative tools. A procedure with a similar objective was performed by $\mathrm{Hu}$ et al. [23], in order to validate GHQ-12 for measuring $\mathrm{PMH}$. After both adaptation steps, we generated a new scale for measuring $\mathrm{PMH}$, maintaining 9 of the original items of GHQ-12. This new scale showed 
moderate internal consistency (Cronbach's alpha) globally and for each separate population (global $=0.61$, rural $=0.61$, migrant $=0.60$, urban $=0.68$, , which are in the acceptable range of 0.60-0.70 for group assessment and group comparisons proposed by Aiken [1]. Exploratory factor analysis showed a one-dimensional solution in every population (see Additional file 1: for a detailed discussion of differences with $\mathrm{Hu}$, and further details about statistical analysis and results).

Sex, age, education and family income variables were measured via the previously-mentioned sociodemographic survey. Age was measured as a continuous variable, although here it has been used in its categorical form (Table 1), given the stratification defined in the sampling design. Education included four levels: no schooling (literate and illiterate), primary education (complete or incomplete), secondary education (high school, complete or incomplete) and superior (undergraduate studies, complete or incomplete). Family income included global income of the participant's family, including his/her own salary; it is referred to as 'income' in the rest of the article.

\section{Statistical analysis}

The first step was to prepare the data for analysis, which included an assessment of the missing values. Next, we conducted an exploratory data analysis, verifying the assumptions of the selected statistical tools. To describe data, we used percentages for categorical variables such as sex, age, education, family income and tobacco consumption (outcome). PMH was treated as a continuous variable and summarised by showing the mean and standard deviation for each population. For bivariate analysis (Table 2), we used simple log-Poisson robust regression models (one model per predictor variable) to estimate prevalence ratios (PR) and a Wald test to obtain $p$ values. Multivariate analysis included estimation of two different models. To assess the association between TC and PMH adjusted by confounders (shown also in Table 2 in every population), we estimated this in Model-1:

$$
\begin{aligned}
\log (T C) & =\beta_{0}+\beta_{1} P M H+\beta_{2} \text { age }+\beta_{3} \text { sex } \\
& +\beta_{4} \text { education }+\beta_{5} \text { income }
\end{aligned}
$$

To evaluate interaction between PMH and groups (rural, migrant and urban), we have created a model that includes the interaction variables group $P M H$ (two dummy variables and one control), henceforth called Model-2:

$$
\begin{aligned}
\log (T C) & =\beta_{0}+\beta_{1} P M H+\beta_{2} \text { age }+\beta_{3} \text { sex } \\
& +\beta_{4} \text { education }+\beta_{5} \text { income }+\beta_{6} \text { group } \\
& +\beta_{7} \text { group } * P M H
\end{aligned}
$$

To diagnose models, we utilised criteria based on loglikelihood: LR Test, Akaike information criteria (AIC) and Bayesian information criteria (BIC). All PR estimations, crude and adjusted, were performed using a robust log-Poisson regression model [5]. We preferred PRs instead of odds ratios because PRs are more appropriate and easier to interpret in cross-sectional studies when the outcome prevalence is high [21, 44, 48]. A power analysis was performed using a simulation-based approach [32], considering 1000 replications for each specified effect size. This analysis has been included in order to supply relevant information for discussion of non-conclusive results $(p>0.05)$. Throughout, $95 \%$ confidence intervals were calculated. Stata 12.0 for Windows (Stata Corporation, College Station, Texas) was used to perform the analysis.

\section{Results}

\section{Participant dataset}

A total of 989 participants responded to the survey. The final number of analysed cases differs among Tables 1, 2 and 3 , given the availability of data (missing complete at

\begin{tabular}{|c|c|c|c|c|c|c|c|c|c|c|c|c|c|c|c|c|}
\hline & \multicolumn{8}{|c|}{ Lifetime TC } & \multicolumn{8}{|c|}{ Recent TC } \\
\hline & \multicolumn{4}{|c|}{ PMH (Crude) } & \multicolumn{4}{|c|}{ PMH (Adjusted) } & \multicolumn{4}{|c|}{ PMH (Crude) } & \multicolumn{4}{|c|}{ PMH (Adjusted) } \\
\hline & $\bar{N}$ & $\mathrm{PR}^{\mathrm{a}}$ & $(\mathrm{Cl}-95 \%)^{\mathrm{b}}$ & $p^{*}$ & $\bar{N}$ & $P R^{a}$ & $(\mathrm{Cl}-95 \%)^{\mathrm{b}}$ & $p^{*}$ & $\bar{N}$ & $P^{a}$ & $(\mathrm{Cl}-95 \%)^{\mathrm{b}}$ & $p^{*}$ & $\bar{N}$ & $P R^{a}$ & $(\mathrm{Cl}-95 \%)^{\mathrm{b}}$ & $p^{*}$ \\
\hline Rural $(N=201)$ & 98 & 0.96 & $(0.91-1.0)$ & 0.12 & 156 & 0.93 & $(0.87-0.99)$ & 0.02 & 198 & 0.99 & $(0.89-1.1)$ & 0.77 & 156 & 0.94 & $(0.83-1.1)$ & 0.33 \\
\hline Migrant $(N=589)$ & 476 & 1.0 & $(1.0-1.1)$ & 0.01 & 448 & 1.0 & $(0.97-1.0)$ & 0.96 & 483 & 1.2 & $(1.1-1.4)$ & $<0.01$ & 455 & 1.1 & $(1.0-1.3)$ & 0.06 \\
\hline Urban $(N=199)$ & 161 & 0.99 & $(0.95-1.0)$ & 0.74 & 155 & 0.96 & $(0.92-1.0)$ & 0.07 & 163 & 1.1 & $(0.90-1.2)$ & 0.54 & 157 & 0.98 & $(0.85-1.1)$ & 0.75 \\
\hline
\end{tabular}
random assumption has been verified and pairwisedeletion procedure applied). The highest proportion of missing values was found for income (8.5\%) and $\mathrm{PMH}$

Table 2 Prevalence ratios (Crude and Adjusted) of tobacco consumption (TC) by rural, migrant and urban groups

${ }^{a}$ Crude prevalence ratio (PR) has been obtained by a simple log-poisson robust regression model. Adjusted prevalence ratio (PR) has been obtained by the same log-poisson robust regression model, but adjusted by sex, age, education and income. ${ }^{b}$ Confidence Intervals $95 \%$. *Wald test PMH Positive Mental Health Lifetime TC: Have you ever smoked a cigarette? Recent TC: Are you currently smoker? or Have you smoked in the last six months? Source: PERU MIGRANT Study dataset 
Table 3 Prevalence ratios (Crude and Adjusted) of tobacco consumption (TC) in migrant population by age of migration and time of residence

\begin{tabular}{|c|c|c|c|c|c|c|c|c|c|c|c|c|c|c|c|c|}
\hline & \multicolumn{8}{|c|}{ Lifetime TC } & \multicolumn{8}{|c|}{ Recent TC } \\
\hline & \multicolumn{4}{|c|}{ PMH (Crude) } & \multicolumn{4}{|c|}{ PMH (Adjusted) } & \multicolumn{4}{|c|}{ PMH (Crude) } & \multicolumn{4}{|c|}{ PMH (Adjusted) } \\
\hline & $\bar{N}$ & $P R^{a}$ & $(\mathrm{Cl}-95 \%)^{\mathrm{b}}$ & $p^{*}$ & $\bar{N}$ & $P R^{a}$ & $(\mathrm{Cl}-95 \%)^{\mathrm{b}}$ & $p^{*}$ & $\bar{N}$ & $P R^{a}$ & $(\mathrm{Cl}-95 \%)^{\mathrm{b}}$ & $p^{*}$ & $\bar{N}$ & $P R^{a}$ & $(\mathrm{Cl}-95 \%)^{\mathrm{b}}$ & $p^{*}$ \\
\hline \multicolumn{17}{|l|}{ Age of migration } \\
\hline $0-12$ years & 163 & 1.1 & $(1.0-1.1)$ & 0.04 & 154 & 1.0 & $(0.98-1.1)$ & 0.23 & 165 & 1.2 & $(0.98-1.5)$ & 0.08 & $* *$ & $* *$ & $* *$ & $* *$ \\
\hline $12-20$ years & 253 & 1.0 & $(0.99-1.1)$ & 0.18 & 240 & 0.99 & $(0.95-1.0)$ & 0.61 & 258 & 1.2 & $(1.0-1.4)$ & 0.01 & 245 & 1.1 & $(0.95-1.3)$ & 0.19 \\
\hline 20 or more years & 56 & 1.0 & $(0.93-1.2)$ & 0.59 & 50 & 1.0 & $(0.85-1.2)$ & 0.95 & 56 & 1.2 & $(0.86-1.8)$ & 0.26 & 50 & 1.7 & $(0.62-4.7)$ & 0.30 \\
\hline \multicolumn{17}{|l|}{ Time of residence } \\
\hline $0-20$ years & 48 & 1.1 & $(0.98-1.3)$ & 0.11 & 47 & 1.0 & $(0.90-1.2$ & 0.61 & 50 & 1.7 & $(1.1-2.7)$ & 0.03 & 49 & 0.88 & $(0.46-1.7)$ & 0.69 \\
\hline $20-40$ years & 334 & 1.0 & $(1.0-1.1)$ & 0.03 & 318 & 1.0 & $(0.96-1.0)$ & 0.88 & 339 & 1.1 & $(0.97-1.2)$ & 0.15 & 323 & 1.0 & $(0.90-1.2)$ & 0.76 \\
\hline 40 or more years & 89 & 1.0 & $(0.95-1.1)$ & 0.85 & 79 & 0.98 & $(0.91-1.1)$ & 0.56 & 89 & 1.9 & $(1.4-2.5)$ & $<0.001$ & 79 & 2.1 & $(1.5-2.9)$ & $<0.001$ \\
\hline
\end{tabular}

${ }^{a}$ Crude prevalence ratio (PR) has been obtained by a simple log-poisson robust regression model. Adjusted prevalence ratio (PR) has been obtained by the same log-poisson robust regression model, but adjusted by sex, age, education and income. ${ }^{b}$ Confidence Intervals $95 \%$. * Wald test. ** Model does not converge PMH: Positive Mental Health Lifetime TC: Have you ever smoked a cigarette? Recent TC: Are you currently smoker? or Have you smoked in the last six months? Source: PERU MIGRANT Study dataset

(14.9\%). Variable lifetime TC had only $1.3 \%$ of values missing (13 cases).

\section{Participant demographics}

After revision of the population features (Table 1), distributions for education and income were clearly dissimilar. The rural group mostly had a primary education. However, most urban people had a high-school (secondary) or undergraduate (superior) education. Migrants underwent a position of 'transition' between these two groups. Income was similarly distributed with the urban group the richest and the rurals, the poorest. Finally, we detected differences in $\mathrm{PMH}$ and tobacco consumption, with the rural group having lower levels of both variables.

\section{Crude and adjusted association}

For crude associations (Table 2), we observed differences in the crude relationship between $\mathrm{PMH}$ and tobacco consumption among rurals, migrants and urbans. For example, for migrants there was a positive relationship between $\mathrm{PMH}$ and tobacco consumption (both lifetime and recent); however, in rural and urban populations this relationship was negative (at least as a trend). Adjusted results (Model1 for every group) show a negative association between $\mathrm{PMH}$ and tobacco consumption (lifetime) in the rural population: more points on the $\mathrm{PMH}$ scale indicate a higher probability of no tobacco consumption (for every unit of increment on the PMH scale, the probability of consuming tobacco is reduced by $7 \%$ across the mean). In fully adjusted models, there was no evidence of a significant association between PHM and tobacco consumption in urban and migrant groups; however, in migrants the trend for positive association deserves attention. Evaluating Model-2 (using lifetime TC), we found an interaction effect among migrant and rural groups $(p=0.02$, Wald Test) and no interaction effect among migrant and urban groups ( $p=0.06$, Wald Test). However, the global interaction model (Model-2: $\mathrm{AIC}=1440 ; \mathrm{BIC}=1514$ ) was not a better fit than the nested non-interaction model (Model-1: $\mathrm{AIC}=1438 ; \mathrm{BIC}=1502 ; p=0.43$ for the LR test of the nested model with non-robust estimations). Simulation results showed that in the interaction model (Model-2, lifetime TC), the current sample had no more than a $69 \%$ chance of detecting, in urban*PMH interaction, an effect size between -0.04 ( $P R=0.96$ similar to what was observed in this study for this interaction) and -0.10 ( $P R=0.91$, bigger than the -0.08 observed in this study for rural ${ }^{*} \mathrm{PMH}$ interaction).

\section{Association and trends in graphics}

Figure 1 provides a plot of estimated probability of tobacco consumption (Y-Axis) related to direct scaling of $\mathrm{PMH}$ (X-Axis), adjusted by sex, age, education and income. The rural curve shows a change from probabilities of tobacco consumption $>0.80$ at lower points of the PMH scale ( 0 and 1$)$ to probabilities $<0.60$ at higher points of the PMH scale (7, 8 or 9 ). In the urban curve, a similar trend is visible but with a lower magnitude of change: from probabilities of tobacco consumption $>0.80$ at lower points of the PMH scale $(0,1$ and 2$)$ to probabilities $<0.80$ at higher points of the $\mathrm{PMH}$ scale (5, 6, 7 and 8). In migrants, an inverse trend has been observed: from probabilities of tobacco consumption $<0.60$ at the lowest measured point of the PMH scale (1) to probabilities $>0.80$ at the highest point of the PMH scale (9).

\section{Deeper exploration in migrants}

In Table 3, attention returns to the trends of positive association between $\mathrm{PMH}$ and TC in migrants. A deeper 


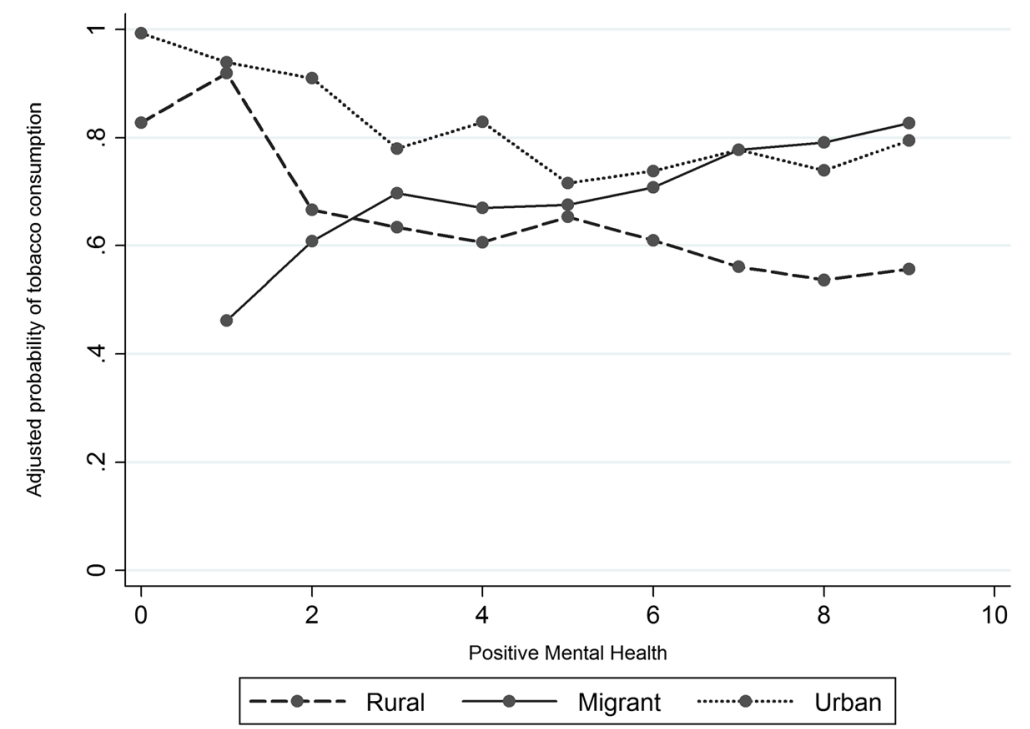

Fig 1 Tobacco consumption and positive mental health for adjusted models by group. Note: the Y-AXIS represents the predicted probability of tobacco consumption, using estimation models adjusted by sex, age, education and income. The X-AXIS corresponds to the direct measurement of the PMH made by our adaptation of the GHQ-12, scaled from 0 to 9

exploration in sub-groups has revealed that migrants who have lived in their new place of residence for $40+$ years show a stronger positive association between $\mathrm{PMH}$ and recent TC than their counterparts. Stratification by age at migration was also explored, but no relevant results were found.

\section{Discussion}

The results showed above can be summarized in two points: 1) PMH is a protective factor against lifetime tobacco consumption only in the rural population ( $\mathrm{PR}=$ $0.93, p=0.02)$; 2) For urban and migrant population we have only detected non-significant and opposite trends: $\mathrm{PMH}$ is protective for lifetime $\mathrm{TC}$ in urbans $(\mathrm{PR}=0.96$, $p=0.07)$, but is risky for recent $\mathrm{TC}$ in migrants $(\mathrm{PR}=$ $1.1, p=0.06)$. We will discuss these results in the next lines.

$\mathrm{PMH}$ is a protective factor against lifetime tobacco consumption only in the rural population (see Table 3 ). This result has been adjusted by sex, age, education and income which are the main factors associated with $\mathrm{TC}$, considering a previous study in rural population [8]. Free of confounding effect, the relationship between $\mathrm{PMH}$ and $\mathrm{TC}$ is $\mathrm{PR}=0.93$, representing an average reduction of $7 \%$ of TC prevalence per every point increased in the PMH scale. This protective association can be explained by a theoretical model where more resilience and happiness can reduce the incidence of anxiety or depressive episodes, both predictive factors of TC. In Peruvian rural population this model has empirical support: they have the highest level of depressive symptoms and tobacco use in the country [31,35] and our study shows that they have the lowest level of $\mathrm{PMH}$. One adult from rural settings, who lives in poverty and usually depends on agriculture to survive, who has not enough access to the health system and receive just a little support from the Government, is susceptible to fall in critical situations that lead him/ her to anxiety or depressive episodes. Those who have developed a strong character for copying the crisis and keep the optimism are covered with a better shield against anxiety and depression. With less incidence of mental illness, these rurals with high PMH can avoid or cease the TC.

For urban and migrant population we have only detected non-significant and opposite trends: $\mathrm{PMH}$ is protective for lifetime TC in urbans, but is risky for recent $\mathrm{TC}$ in migrants. In urbans there is a similar trend of negative association as in rural people (see Fig. 1 and Table 2), and this trend is visibly different from the positive association trend in migrants (for recent TC). However, the statistical results of Model-2 evaluation have shown that these trends are not enough to conclude a significant difference in the studied association between these populations. Nevertheless, with $69 \%$ of maximum power there remains the possibility of committing a type-II error if we conclude there is no interaction effect for the urban population. Given this uncertainty, it is too hasty to conclude that urban groups and migrants are not intrinsically different. Current trends appear to confirm that migrants (rural-to-urban) and non-migrants (rural and urban) both display distinct associations between $\mathrm{PMH}$ and tobacco use. However, new evidence for confirming this difference is needed. 
In spite of inconclusive results about differences in the patterns of association between $\mathrm{PMH}$ and tobacco in the rural, urban and migrant groups, we believe that the different trend in migrants merits discussion. Peruvian migrants have a history of violence because of terrorism (the principal cause of the Peruvian internal migration phenomenon). In this mass historical migration we recognise an effect on the coastal urban culture (Lima), which gives migrants their particular profile [4]. Major changes suffered by migrants have created a challenging process of adaptation that modified their lifestyle, thinking and behaviour. These extreme requirements of 'forced adaptation' (mostly rejected by migrants) have even generated changes in identity that make them a particularly distinct group, alienated from their original culture (rural) and from their new cultural home (urban). This alienation can be expressed through three levels: intrapersonal (related to well-being, self-determination and distress), interpersonal (related to social support), and citizenship (related to sense of belonging, discrimination and stigmatization) [17]. This state of incomplete rural-to-urban cultural transition' may create a particular psychosocial scenario where positive features (intrapersonal) cannot operate with the same social conditions (interpersonal and citizenship) of non-migrants contexts, altering negative association between $\mathrm{PMH}$ and $\mathrm{TC}$ that have been detected in rural non-migrants (original culture of these migrants). Actually, this can be the underlying cause of many of the behavioural differences among migrants and urban or rural non-migrants, and may offer the first clue to explaining the differences detected in our study. For example, from the results of Table 3, it is noticeable that migrants living 40 years or more in an urban area (those who are expected to be more 'acculturated') still have a positive association between $\mathrm{PMH}$ and recent $\mathrm{TC}$ (the opposite of what is visible in Table 2 for the native urban population). We recognise the acculturation process is too complex to be analysed and explained properly with only the current information; however, the evidence presented represents a promising beginning.

Some limitations in our study deserve consideration. First, the instrument used for measuring PMH (GHQ12) was not originally designed for our specific purpose. This problem was offset by a thorough psychometric validation, which included a review of content validity and construct validity (see Additional file 1). Self-report of smoking is another limitation, because it is not the best available measurement of tobacco consumption. However, we believe that the results of this study provide a sufficiently valid approximation (considering that this is a first approach); moreover, 'lifetime prevalence' is a known and used variable in the field of addictive behaviour research and its results are easy to compare with others that come from studies on tobacco consumption $[6,19,26,28,36]$. Also, we did not control for genes associated with smoking because we did not have this information available; nevertheless, we controlled for other relevant potential confounders. Our cross-sectional design prevents us to make causal inferences; however, it is completely acceptable for doing a first approximation of potential causal relationships. Finally, reflecting on the external validity of the study, we maintain that these results can be formally generalised to the populations that our samples represent, but the same results are also transferable with relative confidence to other groups of Peruvian migrants and non-migrants. Thus, it is clear that, despite the inherent limitations to our research, the information obtained is valuable; although it is not conclusive, it is at least relevant. Given that research into $\mathrm{PMH}$ within the field of addiction is still in its infancy, and needs evidence to justify and promote new research, the presentation and dissemination of these results in a timely fashion is important.

We believe that our findings have implications for clinical practice and public health for the rural population in Peru and other similar low and middle income countries (LMIC). Cessation therapies for rural populations can be improved if we consider reinforcing these therapies with positive mental health training. As we have seen, in natural contexts (without systematic training), $\mathrm{PMH}$ can work against tobacco consumption as a protective factor. In this sense, complementary PMH training could help to ensure the durability of the positive effects of traditional psychotherapies beyond the clinical space, where psychotherapists cannot monitor and directly influence patient behaviour. Moreover, PMH training can help to develop new preventive initiatives against tobacco consumption at a public health level. Previous studies have shown increasing evidence about how PMH can help, in a large population, to promote general mental health [20]. With our current evidence, we have more support for translating this positive practice to rural populations from LMICs. In sum, our national efforts in the fight against tobacco consumption can be potentiated thanks to $\mathrm{PMH}$ promotion and training.

\section{Conclusion}

PMH was negatively associated with TC in rural participants only. Urbans exhibited just a similar trend, while migrants exhibited the opposite one. This evidence represents the first step in the route of knowing the potential of $\mathrm{PMH}$ for fighting against TC. For rural populations, this study supplies new information that could support decisions about prevention programmes and psychotherapy for smoking cessation. However, more research in the topic is needed. 


\section{Ethics approval}

The protocol for this study was reviewed and approved by the Universidad Peruana Cayetano Heredia's ethics committee in Peru. The original PERU MIGRANT Study was approved by the same committee, together with the London School of Hygiene and Tropical Medicine.

\section{Consent for publication Not applicable}

\section{Availability of data and materials}

The dataset supporting the conclusions of this article is available in the Figshare repository via: https://figshare.com/articles/PERU_MIGRANT_Study_Baseline_dataset/3125005

\section{Additional file}

Additional file 1: In this Additional file 1, we present validation procedures and evidence for the adaptation of the General Health Questionnaire (GHQ-12) used in this study for measuring positive mental health $(\mathrm{PMH})$. (DOCX $35 \mathrm{~kb})$

\section{Abbreviations}

PMH: positive mental health; TC: tobacco consumption; LMIC: Iow and middle income countries; AIC: akaike information criteria; BIC: bayesian information criteria; PR: prevalence ratio; GHQ-12: general health questionnaire version 12; LR test: likelihood ratio test.

\section{Competing interests}

The authors declare that they have no competing interests.

\section{Author's contributions}

Original idea, study design, statistical analysis and writing of manuscript: JCBA. Advice on study design, statistical analysis and writing of manuscript: ABO, GA and JJM. Revision of manuscript: FP, ABO, GA and JJM. Principal Investigator of original study PERU MIGRANT Study: JJM. All authors read and approved the final manuscript.

\section{Author's information}

JJM is Research Professor at the Department of Medicine, School of Medicine and Director of CRONICAS Center of Excellence in Chronic Diseases, both at Universidad Peruana Cayetano Heredia (UPCH) in Lima, Peru. His works brings together epidemiological and health policy aspects of chronic non-communicable diseases in low- and middle-income countries with emphasis on obesity, hypertension, and diabetes. In Peru, he has established the PERU MIGRANT study, the CRONICAS Cohort study and led the CRASH-2 trial. Dr. Miranda is a Member of PLoS International Advisory Group, Councillor for Latin America \& Caribbean of the International Epidemiological Association and Fellow of Faculty of Public Health of the Royal College of Physicians of the United Kingdom. Dr. Miranda trained in medicine at UPCH and earned a PhD in epidemiology at the London School of Hygiene and Tropical Medicine (UK).

GA is an Associate Professor at School of Public Health, Universidad Peruana Cayetano Heredia (UPCH), Lima, Peru. He's the former director of the Master in Public Health Program at UPCH and the former director of the Epidemiology Bureau at the Regional Government of Lima. He was a NIH/FIC/NIDA supported pre and postdoctoral fellow. Currently, he is a researcher and a consultant in public health and epidemiology. His main research interests are mental health and drug dependence epidemiology.

$\mathrm{ABO}$ is a Research Professor at the School of Public Health and an Associate Investigator at CRONICAS Center of Excellence in Chronic Diseases, both at Universidad Peruana Cayetano Heredia (UPCH) in Lima, Peru. Dr. Bernabé-Ortiz has a strong base in biostatistics and epidemiological methods for populationbased studies and observational studies. He coordinates the CRONICAS Cohort, a cardiopulmonary longitudinal study funded by NHLBI-NIH, and is a coinvestigator of the implementation trial using a low-sodium salt substitute in the north or Peru (Tumbes), funded by NHLBI-NIH as part of the Global Alliance for Chronic Diseases. He previously coordinated, and currently teaches on, the Biostatistics course at the Master Research Epidemiology Program at UPCH. Dr. Bernabé-Ortiz trained in medicine at UPCH and earned a MPH at the University of Washington (USA).

FPA is a Biologist and a Junior Investigator at CRONICAS Center of Excellence in Chronic Diseases at Universidad Peruana Cayetano Heredia $(\mathrm{UPCH})$ in Lima, Peru. He has been working in the Endocrinology and Reproduction Laboratory in UPCH, making researches about pharmacology using medicinal plants to prove their properties in reproductive aspects. He has presented his findings in conferences in Peru, Ecuador Panama and USA. He has completed a Master in Epidemiological Research Program training at UPCH through an NHLBI-NIH supported Fellowship. Mr. Peralta currently makes researches about non-communicable diseases such as obesity and high pressure and is also Professor of Epidemiologic Research at Universidad Católica Sedes Sapientiae. Mr. Peralta graduated from Biology at UPCH.

JCBA is a Psychologist with postgraduate studies in Management of Human Resources, Biostatistics and Epidemiology. His first experiences in research were related to psychometrics, including adaptation, design, and validation of tests for educative and clinical purposes. In Biostatistics, his principal activities were related to performing structural equation models and multiple imputation procedures for research projects at Universidad Peruana Cayetano Heredia (UPCH). In Epidemiology, he received training in the Center of Excellence in Chronic Diseases CRONICAS (NHLBI-UPCH) at the same time he studied in a related Master program. He is a lecturer of Biostatistics at UPCH and former lecturer of Quantitative Psychology at Universidad San Pedro. His current research activities are centralized at CRONICAS and the Peruvian Institute for Psychological and Psychosocial Research (PSYCOPERU).

\section{Acknowledgments}

This article was prepared as part of the activities of the Master of Epidemiological Research offered jointly by the Universidad Peruana Cayetano Heredia (UPCH) and the Center for Tropical Disease Research of the U.S. Navy (NAMRU-6). The Master's programme is part of the programme 2D43 TW007393 "International Training Consortium in Epidemiological Research," sponsored by the Fogarty International Center of the National Institutes of Health (NIH / FIC). The author JCBA prepared this article to complete the graduation requirements of this Master's programme. JCBA is very grateful for the guidance and support received from the teachers and alumni of this programme. Special thanks to Paul George for revisions and comments to improve this article.

\section{Funding}

The data collection of the original PERU MIGRANT Study was funded by the Wellcome Trust (GR074833MA). The design, analysis, interpretation of data and the writing of the manuscript of this study were supported by the Center of Excellence for Chronic Diseases (CRONICAS) of the Universidad Peruana Cayetano Heredia, with funds from the National Institutes of Health NIH-USA (HHSN268200900033C).

\section{Author details}

${ }^{1}$ CRONICAS Center of Excellence in Chronic Diseases, Universidad Peruana Cayetano Heredia, Av. Armendáriz 497Miraflores, Lima, Peru. ${ }^{2}$ School of Public Health and Administration, Universidad Peruana Cayetano Heredia, Lima, Peru. ${ }^{3}$ School of Medicine, Universidad Peruana Cayetano Heredia, Lima, Peru.

Received: 23 July 2015 Accepted: 25 April 2016

Published online: 04 May 2016

\section{References}

1. Aiken LR. Tests psicológicos y evaluación. México: Pearson Educación; 2003.

2. Alarcón R. Desarrollo de una Escala Factorial para Medir la Felicidad. R Interam Psicol. 2006;40(1):7. Retrieved from: http://www.redalyc.org/articulo. oa?id=28440110. (Accessed 12 April 2015).

3. Alarcón R. Psicología de la Felicidad: introducción a la psicología positiva. Lima: Editorial Universidad Ricardo Palma; 2009. 
4. Arellano R. Estilos de vida en el Perú: Cómo somos y pensamos los peruanos del siglo XXI. Lima, Perú: Arellano Investigación de Marketing SA; 2005.

5. Barros A, Hirakata V. Alternatives for logistic regression in cross-sectional studies: an empirical comparison of models that directly estimate the prevalence ratio. BMC Med Res Methodol. 2003;3(1):21. doi:10.1186/1471-2288-3-21.

6. Bell RA, Arcury TA, Chen $\mathrm{H}$, et al. Use of tobacco products among rural older adults: prevalence of ever use and cumulative lifetime use. Addict Behav. 2009;34(8):662-7. doi:10.1016/j.addbeh.2009.03.031.

7. Berry J, Poortinga Y, Segall M, Dasen P. Cross-cultural psychology: Research and applications. Second Edition. Cambridge: Cambridge University Press; 2002.

8. Bhavya B, Nisha C, Ankit S, Joseph EN, Anusha BK, Omkar P, Goud BR. Tobacco use among adults and its associated factors in a rural area in Karnataka, India. J Human Health. 2015;1(2):56.

9. Breslau N, Johnson EO. Predicting smoking cessation and major depression in nicotine-dependent smokers. Am J Public Health. 2000;90(7):1122-7. doi:10.2105/AJPH.90.7.1122.

10. Carpenter MJ, Baker NL, Gray KM, Upadhyaya HP. Assessment of nicotine dependence among adolescent and young adult smokers: a comparison of measures. Addict Behav. 2010;35(11):977-82. doi:10.1016/j.addbeh.2010.06.013.

11. Chen X, Li X, Stanton B, Fang X, Lin D, Cole M, Yang H. Cigarette smoking among rural-to-urban migrants in Beijing, China. Prev Med. 2004;39(4):66673. doi:10.1016/j.ypmed.2004.02.033.

12. Chen X, Stanton B, Li X, Fang X, Lin D. Substance use among rural-to-urban migrants in China: a moderation effect model analysis. Subst Use Misuse. 2008:43(1):105-24. doi:10.1080/10826080701209077.

13. Chockalingam K, Vedhachalam C, Rangasamy S, Sekar G, Adinarayanan S, Swaminathan S, Menon PA. Prevalence of tobacco use in urban, semi urban and rural areas in and around Chennai city, India. PLoS One. 2013;8(10):e76005.

14. Díaz D, Rodriguez-Carbajal R, Blanco A, Moreno-Jiménez B, Gallardo I, Valle C, Dierendonck D. Adaptación española de las escalas de bienestar psicológico de Ryff. Psicothema. 2006;18(3):6. Retrieved from: http://www. psicothema.com/pdf/3255.pdf (Accessed 12 April 2015).

15. Franklin WJ. Spiritual Well Being, Stress, and Coping in Never Smoking, Exsmoking, and Current Smoking African American Women [Doctoral Disertation]: University of Akron; 2008. Retrieved from: https://etd.ohiolink.edu/ rws_etd/document/get/akron1209392807/inline. (Accessed 12 April 2015).

16. Ganga NS, Kutty VR. Measuring positive mental health development of the Achutha Menon centre positive mental health scale. Asia Pac J Public Health. 2015;27(2):NP1893-906.

17. García-Ramírez M, Manuel L, Paloma V, Hernández-Plaza S. A liberation psychology approach to acculturative integration of migrant populations. Am J Community Psychol. 2011;47(1-2):86-97. doi:10.1007/s10464-010-9372-3.

18. Griffin $E$, Moon G, Barnet R. Examining the significance of urban-rural context in tobacco quitline use: does rurality matter? Int J Public Health. 2015;60(3):327-33.

19. Helakorpi S, Martelin T, Torppa J, Patja K, Vartiainen E, Uutela A. Did Finland's tobacco control act of 1976 have an impact on ever smoking? an examination based on male and female cohort trends. J Epidemiol Community Health. 2004;58(8):649-54. doi:10.1136/jech.2003.015925.

20. Herrman H, Saxena S, Moodie R. Promoting mental health: concepts, emerging evidence, practice: a report of the World Health Organization, Department of Mental Health and Substance Abuse in collaboration with the Victorian Health Promotion Foundation and the University of Melbourne: World Health Organization; 2005. Retrieved from: http://www.who.int/mental_ health/evidence/MH_Promotion_Book.pdf (Accessed 12 April 2015).

21. Hirakata VN. Estudos Transversais e Longitudinais com Desfechos Binários: qual a melhor medida de efeito a ser utilizada? Rev HCPA. 2009;29(2):174-6. Retrieved from: http://www.seer.ufrgs.br/index.php/hcpa/article/view/9737/ 5819 (Accessed 12 April 2015).

22. Hodder RK, Daly J, Freund M, Bowman J, Hazell T, Wiggers J. A schoolbased resilience intervention to decrease tobacco, alcohol and marijuana use in high school students. BMC Public Health. 2011;11:722. doi:10.1186/1471-2458-11-722

23. Hu Y, Stewart-Brown S, Twigg L, Weich S. Can the 12-item general health questionnaire be used to measure positive mental health? Psychol Med. 2007;37(07):1005-13. doi:10.1017/S0033291707009993.

24. Jahoda M. Current concepts of positive mental health. New York: Basic Books Inc; 1958. 168 p. doi:10.1037/11258-000.

25. Jarrett T. Warrior Resilience Training in Operation Iraqi Freedom: combining rational emotive behavior therapy, resiliency, and positive psychology. US Army Med Dep J. 2008:32-8. Retrieved from: http://cdm15290.contentdm. oclc.org/cdm/ref/collection/p15290coll3/id/552 (Accessed 12 April 2015).
26. Jeon HJ, Hahm BJ, Lee HW, et al. Prevalence, correlates, and comorbidity of 12-Month tobacco dependence among ever-smokers in South Korea, during 1984-2001. J Korean Med Sci. 2008;23(2):207-12. doi:10.3346/jkms. 2008.23.2.207.

27. Joseph S, Wood A. Assessment of positive functioning in clinical psychology: theoretical and practical issues. Clin Psychol Rev. 2010;30(7): 830-8. doi:10.1016/j.cpr.2010.01.002

28. Kawakami N, Takatsuka N, Shimizu H, Takai A. Life-time prevalence and risk factors of tobacco/nicotine dependence in male ever-smokers in Japan. Addiction. 1998;93(7):1023-32. doi:10.1046/j.1360-0443.1998.93710237.x.

29. Kelloniemi $H$, Ek E, Laitinen J. Optimism, dietary habits, body mass index and smoking among young Finnish adults. Appetite. 2005;45(2):169-76. doi: 10.1016/j.appet.2005.05.001.

30. Lee Duckworth A, Steen TA, Seligman ME. Positive psychology in clinical practice. Annu Rev Clin Psychol. 2005;1:629-51. doi:10.1146/annurev.clinpsy. 1.102803.144154.

31. Loret de Mola C, Stanojevic S, Ruiz P, Gilman RH, Smeeth L, Miranda JJ. The effect of rural-to-urban migration on social capital and common mental disorders: PERU MIGRANT study. Soc Psychiatry Psychiatr Epidemiol. 2011. DOI: 10.1007/s00127-011-0404-6.

32. Luedicke J, editor. Powersim: simulation-based power analysis for linear and generalized linear models. 2013 Stata Conference; 2013: Stata Users Group. Retrieved from: http://econpapers.repec.org/paper/bocnorl13/13.htm (Accessed 12 April 2015)

33. Lukat J, Margraf J, Lutz R, van der Veld WM, Becker ES. Psychometric properties of the positive mental health scale (PMH-scale). BMC Psychol. 2016:4(1):1.

34. Miranda JJ, Gilman RH, García HH, Smeeth L. The effect on cardiovascular risk factors of migration from rural to urban areas in Peru: PERU MIGRANT Study. BMC Cardiovasc Disord. 2009;9(1):23. doi:10.1186/1471-2261-9-23.

35. Miranda JJ, Gilman RH, Smeeth L. Differences in cardiovascular risk factors in rural, urban and rural-to-urban migrants in Peru. Heart. 2011;97(10):787-96.

36. Mushtaq N, Beebe LA, Thompson DM, Skaggs VJ. Smokeless tobacco and prevalence of cardiovascular disease. J Okla State Med Assoc. 2010; 103(11-12):539. Retrieved from: http://europepmc.org/abstract/med/ 21319587 (Accessed 12 April 2015)

37. Orpana H, Vachon J, Dykxhoorn J, McRae L, Jayaraman G. Monitoring positive mental health and its determinants in Canada: the development of the positive mental health surveillance indicator framework. Health Promot. 2016;36(1).

38. Padrão P, Damasceno A, Silva-Matos C, Carreira H, Lunet N. Tobacco consumption in Mozambique: use of distinct types of tobacco across urban and rural settings. Nicotine Tob Res. 2013;15(1):199-205.

39. Pahl K, Brook JS, Koppel J, Lee JY. Unexpected benefits: pathways from smoking restrictions in the home to psychological well-being and distress among urban black and Puerto Rican Americans. Nicotine Tob Res. 2011; 13(8):706-13. doi:10.1093/ntr/ntr062.

40. Palipudi KM, Gupta PC, Sinha DN, Andes LJ, Asma S, McAfee T, Collaborative Group GATS. Social determinants of health and tobacco use in thirteen low and middle income countries: evidence from Global Adult Tobacco Survey. PLoS One. 2012;7(3): e33466.

41. Pesce RP, Assis SG, Avanci JQ, Santos NC, Malaquias JV, Carvalhaes R. Crosscultural adaptation, reliability and validity of the resilience scale. Cad Saude Publica. 2005;21(2):12. doi:10.1590/S0102-311X2005000200010.

42. Phipps S. Adaptive style in children with cancer: implications for a positive psychology approach. J Pediatr Psychol. 2007;32(9):1055-66. doi:10.1093/ jpepsy/jsm06.

43. Sanjuán P, Perez A, Bermúdez J. Escala de autoeficacia general: datos psicométricos de la adaptación para población española. Psicothema. 2000; 12(2):5. Retrieved from: http://www.psicothema.com/pdf/615.pdf (Accessed 12 April 2015).

44. Schiaffino A, Rodríguez M, Pasarín MI, Regidor E, Borrell C, Fernández E. ¿Odds ratio o razón de proporciones? Su utilización en estudios transversales. Gac Sanit. 2003;17:51. doi:10.1157/13043426.

45. Seligman ME, Parks AC, Steen T. A balanced psychology and a full life. Phil Trans R Soc Lond B. 2004;359(1449):1379-81. doi:10.1098/rstb.2004.1513.

46. Seligman ME, Steen TA, Park N, Peterson C. Positive psychology progress: empirical validation of interventions. Am Psychol. 2005;60(5):410-21. doi:10.1037/0003-066X.60.5.410.

47. Spatarella A, Jacobsen D, Kohn N, et al. Self-Efficacy Intervention And Quit Rates Among Participants In A Tobacco Dependence Treatment Program. 
Am J Respir Crit Care Med. 2014;189:A1100. Retrieved from: http://www. atsjournals.org/doi/abs/10.1164/ajrccm-conference.2014.189.1_

MeetingAbstracts.A1100 (Accessed 12 April 2015).

48. Thompson ML, Myers J, Kriebel D. Prevalence odds ratio or prevalence ratio in the analysis of cross sectional data: what is to be done? Occup Environ Med. 1998;55(4):272-7. doi:10.1136/oem.55.4.272.

49. Williams GC, McGregor HA, Sharp D, et al. Testing a self-determination theory intervention for motivating tobacco cessation: supporting autonomy and competence in a clinical trial. Health Psychol. 2006;25(1):91-101. doi:10, 1037/0278-6133.25.1.91.

50. Williams GC, Niemiec CP, Patrick H, Ryan RM, Deci EL. The importance of supporting autonomy and perceived competence in facilitating long-term tobacco abstinence. Ann Behav Med. 2009;37(3):315-24. doi:10.1007/s12160-009-9090-y.

51. Zaman MJ, Loret de Mola C, Gilman RH, Smeeth L, Miranda JJ. The prevalence of angina symptoms and association with cardiovascular risk factors, among rural, urban and rural to urban migrant populations in Peru. BMC Cardiovasc Disord. 2010;10:50. doi:10.1186/1471-2261-10-50.

Submit your next manuscript to BioMed Central and we will help you at every step:

- We accept pre-submission inquiries

- Our selector tool helps you to find the most relevant journal

- We provide round the clock customer support

- Convenient online submission

- Thorough peer review

- Inclusion in PubMed and all major indexing services

- Maximum visibility for your research

Submit your manuscript at www.biomedcentral.com/submit
) Biomed Central 